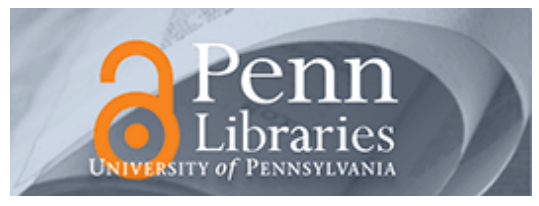

University of Pennsylvania

ScholarlyCommons

Accounting Papers

Wharton Faculty Research

9-2016

\title{
Taste, Information, and Asset Prices: Implications for the Valuation of CSR
}

Henry L. Friedman

Mirko S. Heinle

University of Pennsylvania

Follow this and additional works at: https://repository.upenn.edu/accounting_papers

Part of the Accounting Commons

\section{Recommended Citation}

Friedman, H. L., \& Heinle, M. S. (2016). Taste, Information, and Asset Prices: Implications for the Valuation of CSR. Review of Accounting Studies, 21 (3), 740-767. http://dx.doi.org/10.1007/s11142-016-9359-x

This paper is posted at ScholarlyCommons. https://repository.upenn.edu/accounting_papers/15

For more information, please contact repository@pobox.upenn.edu. 


\title{
Taste, Information, and Asset Prices: Implications for the Valuation of CSR
}

\begin{abstract}
Firms often undertake activities that do not necessarily increase cash flows (e.g., costly investments in corporate social responsibility or CSR), and some investors value these non cash activities (i.e., they have a "taste" for these activities). We develop a model to capture this phenomenon and focus on the assetpricing implications of differences in investors' tastes for firms' activities and outputs. Our model shows that, first, investor taste differences provide a basis for investor clientele effects that are endogenously determined by the shares demanded by different types of investors. Second, because the market must clear at one price, investors' demands are influenced by all dimensions of firm output even if their preferences are only over some dimensions. Third, information releases cause trading volume, even when all investors have the same information. Fourth, investor taste provides a rationale for corporate spin-offs that help firms better target their shareholder bases. Finally, individual social responsibility can lead to corporate social responsibility when managers care about stock price because price reacts to investments in CSR activities.
\end{abstract}

\section{Keywords}

asset pricing, taste, reporting, corporate social responsibility

Disciplines

Accounting 


\title{
Taste, information, and asset prices: Implications for the valuation of CSR
}

\author{
Henry L. Friedman \\ University of California, Los Angeles \\ Mirko S. Heinle \\ University of Pennsylvania
}

November 2015

\begin{abstract}
Firms often undertake activities that do not necessarily increase cash flows (e.g., costly investments in corporate social responsibility, or CSR), and some investors value these noncash activities (i.e., they have a "taste" for these activities). We develop a model to capture this phenomenon and focus on the asset-pricing implications of differences in investors' tastes for firms' activities and outputs. Our model shows that, first, investor taste differences provide a basis for investor clientele effects that are endogenously determined by the shares demanded by different types of investors. Second, because the market must clear at one price, investors' demands are influenced by all dimensions of firm output even if their preferences are only over some dimensions. Third, information releases cause trading volume, even when all investors have the same information. Fourth, investor taste provides a rationale for corporate spin-offs that help firms better target their shareholder bases. Finally, individual social responsibility can lead to corporate social responsibility when managers care about stock price because price reacts to investments in CSR activities.

Keywords: asset pricing; taste; reporting; corporate social responsibility JEL Codes: G11; G12; L30; M40

Henry Friedman can be reached at henry.friedman@anderson.ucla.edu. Mirko Heinle can be reached at miheinle@wharton.upenn.edu. We thank Stefan Wielenberg (discussant), Steven Huddart (discussant), Raffi Indjejikian (discussant), Russel Lundholm (editor), an anonymous referee, and Paul Fischer as well as workshop participants at UCLA, Wharton, Chicago (Booth), Carnegie Mellon, Minnesota, Utah, Ohio State, Maastricht, Tilburg, the Utah Winter Accounting Conference, the Zurich Accounting Research Workshop, and the Review of Accounting Studies Conference for helpful comments and suggestions.
\end{abstract}




\section{Introduction}

The discounted cash flow (DCF) framework provides the foundation for traditional asset pricing theories and suggests that a manager can maximize the firm's stock price by maximizing the net present value of its cash flows. In other words, the amount, timing, and risk of cash flows are the main factors to consider, while the process with which cash flows are generated is not important in and of itself. However, firms' production processes inevitably generate externalities. Broadly defined, production externalities include environmental effects, employee treatment, corporate social responsibility (CSR), and positive or negative publicity about the firm $!^{1}$ While investors should value a dollar of cash flows today similarly, the externalities generated by firms' investments might be valued highly by some investors and valued little (or even ignored) by others. We use a parsimonious model in which investors differ in how they value firms' production externalities to investigate the effects of investor taste on asset prices, and how taste can change how corporate disclosures and real decisions affect asset prices. To fix ideas, we focus on CSR as a motivating example and discuss alternative interpretations of the model below.

Investor preferences for CSR are becoming increasingly important to the allocation of resources $2^{2}$ Trillions of dollars are invested in socially responsible funds that tilt their portfolios in favor of firms that act in socially responsible ways $3^{3}$ Evidence suggests that public pensions and socially responsible investment funds prefer firms with higher CSR ratings while institutional investors overall prefer firms with lower CSR ratings (Di Giuli and Kostovetsky, 2014). In this paper we develop a model to explore the asset-pricing implications of differing

\footnotetext{
${ }^{1}$ Note that CSR and public relations (PR) activities are often undertaken to mitigate negative publicity related to production externalities. We classify CSR and PR activities as externalities broadly because they are peripheral to or indirect consequences of the firm's production process.

${ }^{2}$ Clark and Viehs (2014) provide a review of the literature on CSR and related concepts, focusing on their potential effects on firms' financial and market performance and costs of capital. Huang and Watson (2015) review the CSR literature appearing in accounting journals.

${ }^{3}$ The Forum for Sustainable and Responsible Investment reports that, based on research in mid2012, "\$3.31 trillion in US-domiciled assets was held by 443 institutional investors, 272 money managers and 1,000-plus community investing institutions that select or analyze their portfolios using various ESG [environmental, community, or other societal or corporate governance] criteria." (URL: http: //www.ussif.org/blog_home.asp?Display=6, accessed April 30, 2014).
} 
tastes among investors, building on Fama and French (2007). Specifically, we assume that a representative firm has a production technology that results in stochastic dividends as well as CSR outcomes and that there are two types of investors. While all investors value cash flows similarly, only a fraction of investors value the CSR outcome, which we model as a second output dimension. In this regard, our model departs from the CSR models of Baron 2007, 2009) that focus on firms donating realized cash flows. Our model generates results concerning stock prices, expected returns, market reactions to information, corporate spinoffs, and firms' investment choices that differ in several ways from standard CAPM-style models where investors' preferences are homogeneous.

Our analysis starts with a model of a pure exchange economy with a single risky asset and perfectly competitive, risk-averse investors. We assume that there are two types of investors who we label type 1 and type 2 . The risky asset represents shares in a firm that generates cash and engages in CSR activities, both of which are uncertain. Investors have homogeneous information but heterogeneous tastes. All investors value cash flows, but CSR activities are valued only by type- 2 investors. The model features a trading round in which the price of the risky asset is established and a payout round in which the risky outcomes (e.g., a liquidating dividend and CSR performance) are realized and consumed by investors according to their share ownership. While we assume that type- 2 investors derive utility from owning shares in socially responsible firms, similar to Fama and French (2007) and Gollier and Pouget (2012), we differ from these studies in that we assume that the utility that type-2 investors derive from these shares is not fixed but depends on the actual CSR performance. $\stackrel{4}{4}^{4}$

We analyze the equilibrium share price and find that the mean and variance of both output dimensions are priced as long as there is a non-trivial fraction of type- 2 investors participating in the market. Since we analyze a model with a continuum of heterogeneous

\footnotetext{
${ }^{4}$ While type-1 and type-2 investors may benefit from the firm's pro-social activities even in the absence of share ownership (e.g., lower pollution) we abstract from such welfare externalities to focus on the implications of investor tastes over investments.
} 
risk-averse investors, there is no marginal investor but, instead, shares are priced according to the weighted average preferences of investors. This is similar to a setting where investors have homogeneous preferences but heterogeneous information or heterogeneous beliefs about the distribution of cash flows, where share prices are also defined by average beliefs. 5

Our one-period model of investors with heterogeneous preferences differs from heterogeneousinformation models in key ways. First, in our model investors do not use price to glean any information, in contrast to typical rational-expectations heterogeneous-information models where price is a valuable signal of other investors' information (e.g., Lambert et al., 2007). Second, while our single-period price is the same as that in an "agree-to-disagree" model, in our model no investor ends up being "wrong" in the sense that their beliefs were not rational (e.g., Harris and Raviv, 1993). This implies that there is no need to specify a "correct" outcome distribution or use different distributions for different investors. Third, as the time span represented by a one-period model expands, "agree-to-disagree" assumptions become less plausible because beliefs should converge over time as information is revealed [6 Heterogeneous preferences, in contrast, provide no rationale for long-term convergence. Information, however, still plays an important role when investors have heterogeneous preferences.

We investigate the impact of information in Section 5 where we allow for two rounds of trading. Investors first form portfolios based on their prior beliefs. Information arrives, through, for instance, the firm's public disclosures, and investors rebalance their portfolios by trading based on their revised beliefs. This allows us to derive predictions about the expected costs of capital, returns, and trading around information releases related to both cash flows and CSR outcomes. We find that expected returns and price reactions attributable to CSR disclosures are not only affected by how much information such disclosure provides about CSR outcomes, but also by how much information concurrent disclosures provide

\footnotetext{
${ }^{5}$ More generally, Lintner (1969) and Rubinstein (1974) discuss conditions under which prices can be written as a weighted average of investors' beliefs and preference parameters. Our setting satisfies these conditions.

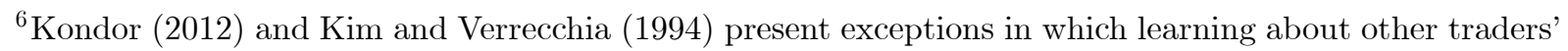
beliefs and heterogeneous processing skills, respectively, cause traders' valuations to diverge even when they receive the same information.
} 
about cash flows. Only type-2 investors value the CSR-related information, so it is their trades and holdings that cause CSR to influence prices. The influence of CSR on prices and returns therefore depends on the fraction of shares owned by type-2 investors before and after informative disclosures, and this fraction, in turn, depends on all investors' uncertainty about cash flows.

Furthermore, in contrast to prior studies involving heterogeneous beliefs and information that derive "no-trade" results (e.g., Milgrom and Stokey, 1982), we find that informative disclosures almost always cause positive trading volume. Even though all investors agree on the information content of the disclosures, heterogeneous preferences drive trade because the same information causes the different investor types to rebalance their portfolios in different ways.

In Section 4 we extend the model to capture a corporate spin-off and find that, because each new firm's shareholder base will generally not be the same as that of the original single firm, total market capitalization can increase or decrease around a spin-off. Consequently, a spin-off can provide the firm with an opportunity to tailor its shareholder base in a way that increases the total share price. In particular, separating one firm into two allows for improved risk sharing between investors, which increases share price. However, as a result of the change in shareholder base, the pricing of the expected CSR outcome changes as well. This causes the spin-off to reduce total stock price when the expected CSR outcome is very high, but also allows the split to be even more value-enhancing when the expected CSR outcome is negative. We therefore predict that managers motivated to increase stock prices are more likely to spin off business segments that have negative expected CSR performance (e.g., the so-called "sin stocks") but keep segments with positive expected CSR performance. 


\section{Related literature}

Our study builds on the recent literature on investor taste and disagreement. Fama and French (2007) provide a framework for asset pricing when investors disagree about fundamentals or have heterogeneous private valuations (i.e., taste). They focus on situations where investors either derive a non-random utility from their share holdings or where fundamental returns influence tastes for assets. In our setting the extra taste-based utility derived from share holdings is risky, because it depends on a risky CSR outcome, and does not depend on financial returns, because we assume additively separable utility and no covariance between fundamentals and CSR. Rahi and Zigrand (2014) explore how differences in private valuations affect the informativeness of price. Jarrow (1980) examines potential effects of short-sale restrictions in a market where investors have different preferences. As in these studies, our taste-based model is closely related to models featuring investors who disagree about the distributions of financial returns (e.g., Harris and Raviv, 1993; He and Shi, 2012). We discuss this and other interpretations of our model in Section 6.2,

Our model generates results related to recent studies on the importance of information about firms' CSR activities and firms' commitments to disclosing such information. Dhaliwal et al. (2011, 2012) find that CSR disclosures affect analyst following and the properties of analysts' forecasts, potentially by changing the demand for analysts indirectly through an effect on the firm's investor base. Serafeim (2014) finds that firms that integrate their reporting of financial performance and sustainability activities (i.e., a dimension of CSR) tend to experience a shift towards more long-term and less short-term institutional investors. Martin and Moser (2014), in a controlled laboratory experiment, find that investors positively value managers' decisions to contribute to an environmental charity, and respond positively to disclosures of such contributions even when they reduce firm cash flows. Bénabou and Tirole (2010) discuss relations between individual and corporate social responsibility, and their potential benefits and costs to social welfare. They highlight the importance of information about CSR and how well-studied issues in financial reporting (e.g., reporting externalities, 
intermediaries, aggregation, and benchmarking) are also important to CSR reporting. Baron (2007, 2009) and Graff Zivin and Small (2005) present models with investors who value firms' charitable contributions or activities to mitigate externalities (termed "moral management") in a setting where investors can also contribute their own cash for similar purposes. These studies develop some results on how investor preferences for moral management [MH: John suggested moral management seems more specific and that we could be more general and just use CSR (or externalities)]can affect stock prices that relate closely to special cases of our baseline model, but the focus of these studies is generally on why and how managers choose to engage in costly CSR activities including charitable donations. Bagnoli and Watts (2014) explicitly model uncertainty about a firm's CSR activities, providing a justification based on information asymmetry for CSR disclosures and assurance of such disclosures. Their setting includes both Bayesian and heuristic users of the disclosures who are not necessarily investors and, as such, Bagnoli and Watts (2014) do not model a capital market or pricing mechanism explicitly. In contrast, we focus on a capital market setting with symmetric information to show how information affects returns and share holdings when some investors, while rational, gain utility from CSR (e.g., due to a "warm glow" or consumption benefit).

CSR disclosures could be related to returns because they are indirectly informative about the firm's future cash flows or because some investors intrinsically care whether a company, for example, pays a fair wage and provides acceptable working conditions to all of its employees. In their review of the literature, Cheng et al. (2014) note that CSR activities could affect corporate financial performance by influencing stakeholder (e.g., employee) engagement or product market demand and by providing private benefits to managers that are costly to shareholders, akin to free-cash flow problems. Given the multitude of effects on employees, customers, and managers, it is not surprising that the empirical evidence on the relation between CSR and corporate financial performance is mixed and inconclusive (see, Cheng et al. (2014), Clark and Viehs (2014), and Bénabou and Tirole (2010)). While the associations between CSR and financial performance are important, our model abstracts away from such 
links. Our focus is instead more aligned with recent research showing that CSR activities are associated with shareholder base or clientele effects. Kim et al. (2014), for example, provide evidence that firms with higher CSR ratings have broader ownership - more institutional and individual investors hold these firms' shares. They also find that higher CSR ratings are associated with greater demand for information as reflected in Google and EDGAR search volume. Dhaliwal et al. (2011) find that firms initiating disclosure of CSR activities, who presumably have positive CSR activities to disclose, tend to attract institutional investors. Robinson et al. (2011) and Hawn et al. (2014) show that the addition of a firm to the Dow Jones Sustainability Index is associated with positive abnormal returns, consistent with increased investor demand for shares of firms with positive and visible CSR indicators. These findings corroborate our predictions that CSR is associated with investor holdings and that there is complementarity between firm information (about both CSR and fundamentals) and investor demand driven by CSR expectations.

In the next section we introduce the basic model that has one trading round before the risky outputs are realized. Section 4 introduces the possibility of corporate spin-offs. In Section 5 we introduce a second round of trading in the same asset after information is released but before all uncertainty is resolved. This enables us to make predictions about the firm's expected stock returns without having to assume that the firm's shareholder base remains constant. Finally, in Section 6 we discuss alternative interpretations of our model, derive implications beyond a CSR framework, and conclude.

\section{The basic model}

As a first step, we consider a two-period model with a single firm: in the first period investors choose portfolios and in the second period the assets in the portfolios realize value. There is one risk-free asset, money, which has a constant price and return of 1, and one risky asset, which represents ownership shares in the firm. We assume that the firm generates per-share 
cash flows of $\tilde{x}$ which result in a liquidating dividend. Furthermore, we express the outcome of the firm's production externalities (i.e., the CSR outcome) in dollar terms as $\tilde{y}$ per share $]^{7}$ We assume that all random variables are normally distributed, with

$$
\begin{aligned}
& E[\tilde{x}]=\bar{x}, \operatorname{Var}[\tilde{x}]=\sigma_{x}^{2}, \\
& E[\tilde{y}]=\bar{y}, \operatorname{Var}[\tilde{y}]=\sigma_{y}^{2}, \text { and } \\
& \operatorname{Cov}[\tilde{x}, \tilde{y}]=0 .
\end{aligned}
$$

Cash flows and CSR outcomes are not correlated. This precludes investors from using information about $\tilde{y}$ to make inferences about $\tilde{x}$. Therefore, the zero-covariance assumption allows us to abstract from results that are based on using $\tilde{y}$ to learn about fundamentals represented by $\tilde{x}$. Allowing $\operatorname{Cov}[\tilde{x}, \tilde{y}] \neq 0$ would not qualitatively affect our results, as we show in Appendix B.8

\subsection{Investors and their preferences}

There is a continuum of risk-averse investors, with unit mass, who can invest in the firm's shares and the risk-free asset. While all investors have constant absolute risk aversion (CARA) and value $\tilde{x}$, only a fraction, $\lambda \in[0,1]$, of the investors values $\tilde{y}$. We distinguish investors by using the index $i \in\{1,2\}$ to denote type- 1 and type- 2 investors. That is, type- 1 investors are indifferent across realizations of $\tilde{y}$, while type-2 investors' utility depends non-trivially on $\tilde{y} !^{9}$ We focus on a two-type setting as the most parsimonious way to capture

\footnotetext{
${ }^{7}$ We can think of the firm's shares as claims to bundled outcomes. There may be scope for an intermediary or the firm to unbundle the firm's cash flows and CSR activities and sell shares of $\tilde{x}$ and shares of $\tilde{y}$ separately. If this unbundling is costly, we expect it to be imperfect and for bundling to persist in equilibrium. For example, it is nearly impossible to perfectly unbundle a firm's treatment of its employees from the firm's cash flows. For simplicity, we do not explore the possibility of unbundling here, but address it in Section 4 on spin-offs.

${ }^{8}$ Empirically, the relation between CSR and financial performance seems ambiguous (see the discussion in Hirigoyen and Poulain-Rehm (2014)). Our assumption simply implies that one-period CSR performance and financial performance are stochastically independent.

${ }^{9}$ Type-2 investors' valuation of $\tilde{y}$ could be due to a "warm glow" related to being an owner of a firm with a positive externality (Andreoni, 1989).
} 
heterogeneous taste over production externalities or CSR. We assume that a type-1 investor's utility is given by $u_{1}=-\exp \left[-r\left(q_{1} \tilde{x}+l_{1}\right)\right]$, where $q_{1}$ and $l_{1}$ represent the quantities of shares in the risky and risk-free asset held by the type- 1 investor, respectively, and $p$ represents the firm's price per share. The utility of type-2 investors is multiplicatively separable in $\tilde{x}$ and $\tilde{y}$ such that $u_{2}=-\exp \left[-r\left(q_{2} \tilde{x}+l_{2}\right)\right] \cdot \exp \left[-r q_{2} \tilde{y}\right]=-\exp \left[-r\left(q_{2}(\tilde{x}+\tilde{y})+l_{2}\right)\right]$.

We effectively assume that type- 2 investors are risk averse in both output dimensions (e.g., cash flows and CSR). While the risk aversion assumption is standard with regard to cash flows, there is no current standard for whether investors are, on average, risk averse, risk neutral, or risk seeking with regard to outcomes like CSR. The nature of some of our results depend on type-2 investors caring about risk related to $\tilde{y}$, so some curvature in their utility with respect to $\tilde{y}$ is important. Without curvature, they would not care about the variance of $\tilde{y}$, and this would change how they react to information. Consistent with our characterization of risk averse type-2 investors, recent experimental evidence suggests that individual donors are risk averse in the outcomes that stem from their donations (e.g., Brock et al. 2013; Exley, 2015). That is, recent experimental evidence provides a basis for assuming that individuals are risk averse in outcomes other than cash flows 10

Each investor maximizes her expected terminal utility subject to the budget constraint $w_{i}=q_{i} p+l_{i}$, where $w_{i}$ is the initial wealth endowment. Substituting the budget constraint, it is straightforward to show that maximizing expected utility is equivalent to maximizing the following certainty equivalent:

$$
C E_{i}=q_{i}\left(E\left[\tilde{v}_{i}\right]-p\right)-\frac{1}{2} r q_{i}^{2} \operatorname{Var}\left[\tilde{v}_{i}\right]
$$

where $\tilde{v}_{1}=\tilde{x}$ and $\tilde{v}_{2}=\tilde{x}+\tilde{y}$ denote the value of the firm's per-share outcome to type-1 and type-2 investors, respectively. This implies that $\operatorname{Var}\left[\tilde{v}_{1}\right]=\operatorname{Var}[\tilde{x}]=\sigma_{x}^{2}$ and $\operatorname{Var}\left[\tilde{v}_{2}\right]=$ $\operatorname{Var}[\tilde{x}]+\operatorname{Var}[\tilde{y}]=\sigma_{x}^{2}+\sigma_{y}^{2}$.

\footnotetext{
${ }^{10}$ Furthermore, Lam et al. (2015, abstract) find that firms with unclear overall CSR performance (positive performance in some dimensions and negative performance in others) are "mispriced by the market compared to their 'neutral' peers, plausibly due to the ambiguity in their social performance."
} 
To maximize efficiency it is beneficial to: (i) allocate the cash flow risk such that each investor holds the same amount, since all investors are equally risk averse; (ii) allocate the CSR outcome risk such that type-1 investors hold all of it; and (iii) allocate the expected CSR outcome such that type-2 (type-1) investors hold any possible positive (negative) amount. The three efficiency dimensions cannot be satisfied simultaneously because they imply different allocations of shares across investors. In equilibrium, share allocations and the price of the risky asset will reflect the balancing of the three dimensions of efficiency.

\subsection{Baseline equilibrium asset price}

Maximizing $C E_{i}$ as given in (1) yields the optimal demand for a type- $i$ investor:

$$
q_{i}=\frac{E\left[\tilde{v}_{i}\right]-p}{r \operatorname{Var}\left[\tilde{v}_{i}\right]}
$$

Prices are set such that aggregate demand equals aggregate supply. There is one share per investor so that, on average, the following market-clearing condition has to hold

$$
(1-\lambda) q_{1}+\lambda q_{2}=1
$$

Lemma 1 shows the equilibrium stock price, which is derived by substituting investors' optimal demand into the market-clearing condition ${ }^{11}$

Lemma 1 The share price, $p$, is given by

$$
p=\bar{x}-r \sigma_{x}^{2}+\frac{\lambda \sigma_{x}^{2}}{\sigma_{x}^{2}+(1-\lambda) \sigma_{y}^{2}}\left(\bar{y}-r \sigma_{y}^{2}\right) .
$$

On a fundamental level, Lemma 1 shows that non-cash flow related outputs of a firm are priced when a fraction of investors value these outputs. Note that when $\lambda \rightarrow 0$, the price

\footnotetext{
${ }^{11}$ Our expression for price in Lemma 1 is equivalent to the price that would prevail in an agree-to-disagree exchange economy with heterogeneous beliefs, and could be derived using the consensus beliefs methodology of Lintner (1969) and Rubinstein (1975), and as discussed in He and Shi (2012).
} 
approaches that in the standard framework with only type- 1 investors, i.e., $p_{\lambda=0}=\bar{x}-r \sigma_{x}^{2}$. When $\lambda \rightarrow 1$, the price approaches that in a standard framework with $y$ as a second cash flow, i.e., $p_{\lambda=1}=\bar{x}+\bar{y}-r\left(\sigma_{x}^{2}+\sigma_{y}^{2}\right)$. In general, price is a weighted average of the price when $\lambda \rightarrow 0$ and the price when $\lambda \rightarrow 1: p=(1-\phi) p_{\lambda=0}+\phi p_{\lambda=1}$, where $\phi=\frac{\lambda \sigma_{x}^{2}}{\sigma_{x}^{2}+(1-\lambda) \sigma_{y}^{2}}$. The fact that price reflects a weighted average of investors' preferences is similar to settings where all investors value cash flows but have different beliefs or information (e.g., Milgrom and Stokey, 1982). One main difference in our setting is that the second dimension is not necessarily cash-flow related. Additionally, all investors agree on the distributions of both dimensions.

Furthermore, because only type-2 investors are interested in the CSR outcome, the weight, $\phi$, on $y$-related terms in the price equation in (4) is determined by the amount of shares held by type- 2 investors. A naive guess is that a fraction $\lambda$ are held by type- 2 investors, reflecting their market presence. However, this is not the case because individuals' holding decisions are determined by expected returns and the riskiness of returns, which vary across investor classes. In equilibrium, the per-share holdings of type- 1 and type-2 investors are given by

$$
\begin{aligned}
(1-\lambda) q_{1} & =(1-\lambda) \frac{-\frac{\lambda}{r} \bar{y}+\left(\sigma_{x}^{2}+\sigma_{y}^{2}\right)}{\sigma_{x}^{2}+(1-\lambda) \sigma_{y}^{2}} \text { and } \\
\lambda q_{2} & =\lambda \frac{\frac{1-\lambda}{r} \bar{y}+\sigma_{x}^{2}}{\sigma_{x}^{2}+(1-\lambda) \sigma_{y}^{2}}
\end{aligned}
$$

The weight $\phi$ is in fact different from $\lambda$ because CSR outcome risk causes type-2 investors to reduce their demand for the firm's shares. The impact of type-2 investors on the pricing of expected CSR outcomes is the same as their influence on the pricing of the riskiness of CSR outcomes, consistent with their pricing power being driven by their positions in the risky asset.

Corollary 1 provides comparative static results for the price in (4).

Corollary 1 Equilibrium share price increases in the expected value of $\tilde{y}$, and can increase 
or decrease in the fraction of type-2 investors and the variances of cash flows and CSR outcomes: $\frac{d p}{d \bar{y}}>0, \frac{d p}{d \lambda} \propto\left(\bar{y}-r \sigma_{y}^{2}\right) \gtrless 0, \frac{d p}{d \sigma_{y}^{2}} \propto-\left(\bar{y}(1-\lambda)+r \sigma_{x}^{2}\right) \gtrless 0$, and $\frac{d p}{d \sigma_{x}^{2}} \propto-r+$ $\frac{\bar{y} \lambda(1-\lambda) \sigma_{y}^{2}}{\lambda \sigma_{x}^{4}+(1-\lambda)\left(\sigma_{x}^{2}+\sigma_{y}^{2}\right)^{2}} \gtrless 0$.

Corollary 1 analyzes the effects of the four essential parameters in our model: the fraction of type-2 investors; the expected CSR outcome; and the variances of cash flows and CSR outcomes. While $\lambda$ parameterizes the heterogeneity of the population, the remaining 3 parameters affect the utilities of investors who hold shares in the asset. Specifically, holding price constant, while an increase in $\sigma_{x}^{2}$ decreases the expected utility of all traders, an increase in $\bar{y}\left(\sigma_{y}^{2}\right)$ increases (decreases) a type-2 investor's utility but does not affect a type-1 investor's utility.

Taken together, an increase in $\bar{y}$ increases the equilibrium price through two effects that reinforce each other. First, $\bar{y}$ has a direct positive impact on price. Second, increasing $\bar{y}$ makes type-2 investors trade more positively which further increases the positive impact of $\bar{y}$ on price. The uncertainty about cash flows and CSR outcomes affects how $\bar{y}$ influences price, since the uncertainties affect the demands from type- 1 and type- 2 investors (i.e., the endogenous degree of investor clienteles). Specifically, the effect of $\bar{y}$ on price is increasing in $\sigma_{x}^{2}$ and is decreasing in $\sigma_{y}^{2}$. That is, an increase in $\sigma_{y}^{2}$ causes type-2 investors to take weaker positions and to discount expected outcomes more. If $\bar{y}$ is positive (or not too negative), then this has a negative effect on price. For sufficiently negative $\bar{y}$ (i.e., $\bar{y}<<0$ ), the effect of an increase in $\sigma_{y}^{2}$ can be positive, since higher $\sigma_{y}^{2}$ decreases the type-2 investors' shareholdings which, in turn decreases the negative influence of $\bar{y}$ on price.

Increases in the fraction of type- 2 investors, $\lambda$, can have positive or negative effects. The reason is that while type-2 investors include $\bar{y}$ in their valuation of the firm's shares, they also include $\sigma_{y}^{2}$. Therefore, when the expected CSR outcome is sufficiently positive (i.e., $\bar{y}>r \sigma_{y}^{2}$ ), increasing the fraction of type-2 investors has a positive effect on price because they impound the positive $\bar{y}$ more strongly into price. When this is not the case (i.e., $\bar{y}<r \sigma_{y}^{2}$ ), the negative effect of an increase in type-2 investors is driven by an increase in the total risk perceived 
by the firm's shareholder base.

There are two potentially countervailing effects of increasing $\sigma_{x}^{2}$ on the firm's share price. First, an increase in $\sigma_{x}^{2}$ increases the risk perceived by all investors. Second, an increase in $\sigma_{x}^{2}$ increases the equilibrium share holdings of type-2 investors. While higher values of $\sigma_{x}^{2}$ decrease the demand of all investors (holding price constant) this effect is stronger for type-1 investors. In equilibrium, price decreases and the total amount of shares held by type- 2 investors increases. When investors have homogeneous preferences, an increase in risk has an unambiguously negative effect on price (i.e., $\lim _{\lambda \rightarrow 0} \frac{d p}{d \sigma_{x}^{2}}=\lim _{\lambda \rightarrow 1} \frac{d p}{d \sigma_{x}^{2}}=-r$ ). However, when $\bar{y}$ is sufficiently positive (i.e., $\bar{y}>\frac{r\left(\sigma_{x}^{2}+\sigma_{y}^{2}\right)^{2}}{\sigma_{y}^{2} \lambda}+\frac{r \sigma_{x}^{4}}{\sigma_{y}^{2}(1-\lambda)}$ ), the second effect can dominate the first and an increase in risk associated with $\tilde{x}$ increases the firm's stock price.

\section{Spin-offs}

In this section we analyze whether investor taste for CSR can play a role in firms' spin-off (or merger) decisions. The baseline model shows that the firm's shareholder base is a result of its fundamental parameters (the distribution of cash and CSR outcomes) and that the price of the firm, in turn, depends on the shareholder base. When a firm spins off a part of its business into a separate company, the fundamental parameters of the two firms will differ from those of the original company. This in turn implies that the aggregate shareholder base of the company will change, which could provide firms with an avenue to increase equity value.

As an example, take Altria, which in the early 2000s was a conglomerate including tobacco (Philip Morris) and packaged food (Kraft) businesses. In the context of our model, type-2 investors might have an aversion to investing in a tobacco business, but would not have the same aversion to investing in a packaged food business. In 2007, Altria spun off its Kraft Foods segment and stated that "The separation of Altria and Kraft will [...] permit Altria and Kraft to target their respective shareholder bases more effectively... ."12

\footnotetext{
${ }^{12}$ Altria Group Inc. Press Release dated March 30, 2007, and accessed on March 16, 2015 at
} 
To stay with the Altria example, we begin with a unified firm with output components $\tilde{x}_{u}$ and $\tilde{y}$. The cash flow component has two sub-components, $\tilde{x}_{u}=\tilde{x}_{k}+\tilde{x}_{a}$, with the subscript $u$ denoting a unified firm. The setup allows us to model a spin-off of $\tilde{x}_{k}$ (e.g., Kraft's cash flows) from the still-bundled $\tilde{x}_{a}$ and $\tilde{y}$ (e.g., Altria's cash flows and CSR performance) ${ }^{13}$ We assume that the random output components are distributed independently and normally, such that, similar to above,

$$
\begin{aligned}
& E\left[\tilde{x}_{i}\right]=\bar{x}_{i}, \operatorname{Var}\left[\tilde{x}_{i}\right]=\sigma_{x_{i}}^{2}>0, \\
& E[\tilde{y}]=\bar{y}, \operatorname{Var}[\tilde{y}]=\sigma_{y}^{2}>0, \text { and } \\
& \operatorname{Cov}\left[\tilde{x}_{k}, \tilde{x}_{a}\right]=\operatorname{Cov}\left[\tilde{x}_{i}, \tilde{y}\right]=0, \forall i \in\{k, a\} .
\end{aligned}
$$

The unified firm can be traded as one firm or split into two firms. If the firm splits, the outputs of the two firms are $\tilde{x}_{a}$ for firm $a$ and $\tilde{x}_{k}+\tilde{y}$ for firm $k$.

From equation (4) above, the share price of the unified firm, $p_{u}$, can be written as

$$
p_{u}=\bar{x}_{u}-r \sigma_{x_{u}}^{2}+\left(\bar{y}-r \sigma_{y}^{2}\right) \frac{\lambda \sigma_{x_{u}}^{2}}{\sigma_{x_{u}}^{2}+(1-\lambda) \sigma_{y}^{2}}
$$

We assume that a spin-off results in one share of firm $a$ and one share of firm $k$ per investor. This implies that investors will face the exact same risk per capita, irrespective of the spinoff, such that there is no benefit from diversification. With this assumption, the post-split

$\overline{\text { http://investor.altria.com/phoenix.zhtml?c }}=80855 \& \mathrm{p}=$ irol-newsArticle\&ID=956368. Note that the spin-off was well-anticipated and motivated by additional purposes (e.g., management focus and corporate debt capacity) that are outside of our model. Furthermore, we make no attempt to examine price reactions around specific dates or attribute abnormal returns or volume to shareholder base effects. Instead, we focus on the market valuation of the firm either as a single unit or as two spun-off components.

${ }^{13}$ The uncertainty in $\tilde{y}$ could be related to the realized health impact of Philipp Morris cigarettes and the unknown extent of cigarette marketing directed at teenagers and children. 
prices for firms 1 and $2, p_{k}$ and $p_{a}$, are 14

$$
\begin{aligned}
& p_{k}=\bar{x}_{k}-r \sigma_{x_{k}}^{2}, \text { and } \\
& p_{a}=\bar{x}_{a}-r \sigma_{x_{a}}^{2}+\left(\bar{y}-r \sigma_{y}^{2}\right) \frac{\lambda \sigma_{x_{a}}^{2}}{\sigma_{x_{a}}^{2}+(1-\lambda) \sigma_{y}^{2}} .
\end{aligned}
$$

In the comparison of the unified firm with the split firm we focus on the total market value, as market value is important in a number of settings closely related to our model. Market value corresponds to the expected utility of an unmodeled entrepreneur (or prior period shareholders) who is selling her shares in the firm. If the entrepreneur sells all her shares before any consumption occurs or information is released, price is a deterministic function of known parameters and the entrepreneur is not exposed to any risk. Similarly, in an overlapping generations model, an older generation of shareholders who have already consumed last-period's $\tilde{x}$ and $\tilde{y}$ are only concerned with the deterministic price they receive from selling shares. We are therefore agnostic about the type or risk-aversion of the hypothetical entrepreneur (or of the initial shareholders). Alternatively, a manager compensated on the basis of stock price would be interested in maximizing stock price, and would similarly face no price-related risk. Finally, price is observable in public markets, which facilitates empirical tests. Our assumption of one share in each firm per investor both pre- and post-split implies that the total market value of the two firms post-split exceeds that of the unified firm whenever $p_{k}+p_{a}>p_{u}$. The following proposition investigates when a spin-off increases the market value of the firm.

Proposition 1 When $\lambda \in(0,1)$, the total market value of the split firms is greater than the market value of the unified firm if and only if $r \sigma_{y}^{2}>\bar{y}$. If $\lambda=0, \lambda=1$ or $r \sigma_{y}^{2}=\bar{y}$, then $p_{a}+p_{k}=p_{u}$.

When $\lambda=1$ or $\lambda=0$, splitting the unified firm (or combining firms $a$ and $k$ ) has no effect on total stock price. If investors are homogeneous, there is no scope for shareholder base

\footnotetext{
${ }^{14}$ We derive prices in a two-firm economy in the proof to Proposition 1 in the Appendix.
} 
effects, and splitting the firm has no effect under our assumptions. In other words, merely creating two independent securities does not in and of itself improve risk sharing.

The $r \sigma_{y}^{2}>\bar{y}$ condition in Proposition 1 consists of two terms, one for the mean of CSR, $\bar{y}$, and one for the effect of CSR variance on type-2 investors, $r \sigma_{y}^{2}$. The intuition for the condition relates to the importance of risk sharing in a market with heterogeneous investors. Specifically, the CSR variance term captures the risk-sharing benefit of splitting the firm. Type-1 and type-2 investors disagree about the risk of firm $a$. When the firms are bundled together, both types of investors are effectively forced to hold the same proportional exposure to firms $a$ and $k$. When the firms are split, each type of investor adjusts their proportional holdings in firms $a$ and $k$. This implies that with a split firm, type-2 investors can decrease their exposure to $\tilde{y}$ such that the CSR risk is borne by investors that are willing to hold this risk at no extra cost. Risk related to $\tilde{y}$ causes type- 2 investors hold fewer shares of firm $a$ than they would hold in the unified firm.

In other words, unbundling $\tilde{x}_{k}$ from $\tilde{x}_{a}+\tilde{y}$ provides the capital market with an option to improve risk sharing, which increases the total share price. However, the improved risk sharing can be costly. Specifically, since fewer shares of firm $a$ are held by type-2 investors, the extent to which the expected CSR outcome is priced decreases. This increases total share price whenever the mean is negative, $\bar{y}<0$, but is costly whenever the mean is positive, $\bar{y}>0$. Proposition 1 implies that firms should be more likely to spin-off segments of their business that have negative externalities and should be more likely to remain unified or merge with segments that have positive externalities.

The takeaway from this section is that shareholder base can play an important role in the capital market value created or destroyed in agglomerations, conglomerations, spinoffs, and divestment decisions. There are, of course, other channels through which value is destroyed or created in conglomerates and spin-offs, including managerial focus, divisional cross-subsidization, efficiencies and inefficiencies of internal capital markets, tax benefits of greater debt capacity, and information asymmetries within and across firms (see Berger and 
Ofek, 1995, for a discussion). Our simple model abstracts from these channels and shows how shareholder base effects can favor or inhibit spin-off decisions. These effects provide a basis for the benefit of the Altria-Kraft split described above.

\section{Price reactions, expected returns, and trade around CSR disclosures}

This section extends the baseline model in two ways. First, we allow for the disclosure of information regarding both cash flows and CSR performance. Second, we assume that investors can trade before and after the disclosures. While modeling the release of information allows us to derive predictions on how CSR disclosure affects prices, introducing a second round of trading allows us to discuss expected returns. When investors only care about cash flows but have heterogeneous beliefs the disclosure of information usually causes the beliefs to converge. Our model is different because we focus on preference heterogeneity that is not directly affected by information or disclosures. However, disclosures still affect beliefs, and, because of underlying taste heterogeneity, affect the private valuations of different investors heterogeneously.

In our model, the release of information causes private valuations to diverge, rather than to converge. Prior to the information release, all investors maximize the profits from trading in the first round. In round 2, after the information release, investors use their first round profits to purchase securities that maximize terminal consumption. As such, investors are homogeneous in the first round of trading because they agree about the distribution of the post-information price but rebalance their portfolios to suit their taste-based preferences, yielding heterogeneous portfolios after information is released. As a result of the rebalancing, the disclosure triggers trade even though all investors have optimal holdings before information is disclosed and agree on how to interpret the information. This differs from the no-trade results established by Hakansson et al. (1982), which further suggests that 
heterogeneity of preferences has different implications than heterogeneity of beliefs.

The standard approach to estimating expected returns in a single-period pure-exchange model is to compare the expected terminal output or liquidating dividend of the firm with the firm's stock price. While there is no terminal cash flow for a going concern and returns are realized as the shares are traded on the market, the simplification of focusing on returns in a static model is usually appropriate as long as investor preferences are homogeneous (i.e., as long as the expected stock price at any point in time equals the agreed-upon discounted expected value of output). In the long run, the uncertainty associated with every component of output will be revealed and priced accordingly such that the researcher can take the difference between expected output and the firm's stock price as realized returns.

In our model, however, investors with different preferences disagree about the economic returns between the second round of trading and the outcome realization round. The reason is that only some investors value CSR. One potential solution to the problem of calculating returns would be to use a weighted average based on investor preferences (e.g., ret $t_{\text {total }}=$ $\lambda *$ ret $_{1}+(1-\lambda) *$ ret $\left._{2}\right)$. However, this ignores investors' holdings, which determine prices. Since the composition of the shareholder base depends on the current assessed cash-flow risk, CSR outcome risk, and expected CSR outcome, the composition of the firm's shareholder base can change as information is released. In a one-period model, there is no scope for the shareholder base to change endogenously and, therefore, no scope for returns related to such changes. In a multi-period model, as we show below, a constant shareholder base only arises in knife-edge cases.

To capture the effects of potential changes in shareholder base, we add a second trading period and assume that a financial disclosure and a CSR disclosure are released between the first and second trading rounds. Specifically, we extend the above model in the following way. Investors first trade in period 1 as described above. In period 2 , information about $\tilde{x}$ and $\tilde{y}$ is revealed to all market participants through the disclosures and a second round of trading occurs. The outputs $\tilde{x}$ and $\tilde{y}$ are realized in period 3. Since investors are not wealth 
constrained and live for the entire life of the firm without liquidity shocks, each investor's demand in each of the two periods can be computed independent of all other demands.

The revealed information in period 2 is given by two information signals which are independent of each other. Let the signals be

$$
\begin{aligned}
\tilde{m} & =\tilde{x}+\tilde{\varepsilon}_{m}, \text { and } \\
\tilde{n} & =\tilde{y}+\tilde{\varepsilon}_{n},
\end{aligned}
$$

where $\tilde{\varepsilon}_{m}$ and $\tilde{\varepsilon}_{n}$ are noise terms that are independent of all other random variables, with:

$$
\begin{aligned}
& \varepsilon_{m} \sim N\left(0, \frac{1}{\tau_{m}}\right) \text { and } \\
& \varepsilon_{n} \sim N\left(0, \frac{1}{\tau_{n}}\right)
\end{aligned}
$$

where $\tau_{i}$ denotes the precision of signal $i$. Furthermore, let $\tau_{x}=1 / \sigma_{x}^{2}$ and $\tau_{y}=1 / \sigma_{y}^{2}$ be the prior precisions of $\tilde{x}$ and $\tilde{y}$, respectively. As before, demand is given by the solution to investors' wealth-maximization problem, which, in the second round, takes a similar form as in the baseline model. Let $q_{i, 2}$ be the shares held by a type- $i$ investor after the second round of trade. Equilibrium second-period share demand from investor $i$ is

$$
q_{i, 2}=\frac{E\left[\tilde{v}_{i} \mid m, n\right]-p_{2}}{r \operatorname{Var}\left[\tilde{v}_{i} \mid m, n\right]}
$$

where $p_{2}$ denotes the second round price. The posterior distributions are given by $E[\tilde{x} \mid m, n]=$ $\frac{\bar{x} \tau_{x}+m \tau_{m}}{\tau_{x}+\tau_{m}}, E[\tilde{y} \mid m, n]=\frac{\bar{y} \tau_{y}+n \tau_{n}}{\tau_{y}+\tau_{n}}, \operatorname{Var}[\tilde{x} \mid m, n]=\frac{1}{\tau_{x}+\tau_{m}}$ and $\operatorname{Var}[\tilde{y} \mid m, n]=\frac{1}{\tau_{y}+\tau_{n}}$. We denote $\tau_{x}^{\prime}=\tau_{x}+\tau_{m}$ and $\tau_{y}^{\prime}=\tau_{y}+\tau_{n}$ the posterior precisions of the investors' beliefs regarding $x$ and $y$, respectively.

In the first round of trading, investors effectively maximize their short-term profits, which is equivalent to maximizing the risk-adjusted budget available in the second round of trading for purchasing securities that generate terminal consumption. Maximizing short-term profits 
is achived by choosing

$$
q_{1 i}=\frac{E\left[p_{2}\right]-p_{1}}{r \operatorname{Var}\left[p_{2}\right]} .
$$

Note that $q_{11}=q_{12}$, which implies that in the first round of trading both types of investor have the same demand for shares in the firm. Substituting the investors' demands into the market clearing condition yields the first and second round prices in Proposition 2 .

Proposition 2 The firm's prices before and after disclosure are given by

$$
\begin{aligned}
& p_{1}=\bar{x}-\frac{r}{\tau_{x}}+\frac{\lambda}{1+(1-\lambda) \frac{\tau_{x}^{\prime}}{\tau_{y}^{\prime}}}\left(\bar{y}-r \frac{1}{\tau_{y}^{\prime}} \frac{1+(1-\lambda) \frac{\tau_{x}^{\prime}}{\tau_{y}^{\prime}}+\lambda \frac{\tau_{n}}{\tau_{y}}}{1+(1-\lambda) \frac{\tau_{x}^{\prime}}{\tau_{y}^{\prime}}}\right) \text { and } \\
& p_{2}=\frac{\bar{x} \tau_{x}+m \tau_{m}}{\tau_{x}^{\prime}}-r \frac{1}{\tau_{x}^{\prime}}+\frac{\lambda}{1+(1-\lambda) \frac{\tau_{x}^{\prime}}{\tau_{y}^{\prime}}}\left(\frac{\bar{y} \tau_{y}+n \tau_{n}}{\tau_{y}^{\prime}}-r \frac{1}{\tau_{y}^{\prime}}\right) .
\end{aligned}
$$

Similar to the single period setting, price in both rounds of trading includes the expected value of cash flows, conditional on all available information. Although investors receive no cash flows before trading in round $2, p_{1}$ includes the expected value of $p_{2}$, and therefore includes $\bar{x}$ by the law of iterated expectations. While the same holds true for the expected CSR outcome, only a fraction $\lambda\left(1+(1-\lambda) \frac{\tau_{x}^{\prime}}{\tau_{y}^{\prime}}\right)^{-1}$ of shares will be held by type-2 investors after the second round of trading. This implies that the expected round 2 shareholdings of type- 2 investors matter for the price impact of $\bar{y}$ on the round 1 price. Note that the risk premium in the second round is the same as the risk premium in our single period setting, using conditional distributions. In the first round, investors are not interested in the uncertainty about the terminal consumption but, instead, in the uncertainty about the second round price. This implies that the discount in $p_{1}$ relative to the weighted expected consumption stems both from uncertainty about the second period price and from the predictable discount in the second-period price generated by consumption uncertainty. To separate these two sources of risk, the following corollary establishes the expected returns from the first to the second round of trading (i.e., the cost of capital). 
Corollary 2 The expected stock return, which we use as a proxy for the cost of capital, is given by $R=E\left[\frac{p_{2}-p_{1}}{p_{1}}\right]=\frac{E\left[p_{2}-p_{1}\right]}{p_{1}}$, where

$$
E\left[p_{2}-p_{1}\right]=r \frac{\tau_{m}}{\tau_{x} \tau_{x}^{\prime}}+\left(\frac{\lambda}{1+(1-\lambda) \frac{\tau_{x}^{\prime}}{\tau_{y}^{\prime}}}\right)^{2} r \frac{\tau_{n}}{\tau_{y}^{\prime} \tau_{y}}
$$

We express the expected change in price in $(19)$ as the sum of two terms: the first term reflects a reduction in risk related to $\tilde{x}$ and the second term reflects a reduction in risk related to $\tilde{y}$. Similar to the classical pure-exchange model, the expected return decreases in the expected value of cash flows, $\bar{x}$, and the expected CSR output, $\bar{y} .15$ This happens because an increase in $\bar{x}$ or $\bar{y}$ is associated with an increase in the denominator in expected returns $\left(p_{1}\right)$ but no change in the numerator $\left(E\left[p_{2}-p_{1}\right]\right)$.

Similar to a setting where investors have homogeneous preferences, the expected price change is a result of the uncertainty regarding the second round price being resolved through the disclosures. While investors in the first round only bear risk that relates to the disclosure event, $\operatorname{Var}\left[p_{2}\right]$, the expected value that they receive, $E\left[p_{2}\right]$, includes a discount that is proportional to the residual uncertainty. The first term in $\sqrt{19}, r \frac{\tau_{m}}{\tau_{x} \tau_{x}^{\prime}}$, is the discount that investors demand for the exposure to price changes from the cash flow related disclosure. The first round price in (17) includes a discount for the unconditional cash flow variance, which equals the sum of cash flow related price risk that investors bear in the first round and cash flow related consumption risk that they bear in the second round, i.e., $\frac{1}{\tau_{x}}=\frac{\tau_{m}}{\tau_{x} \tau_{x}^{\prime}}+\frac{1}{\tau_{x}^{\prime}}$.

A similar intuition holds for the CSR related risk. However, the price change that results from the CSR disclosure is muted (relative to the change induced by the cash flow disclosure) because only some investors value CSR ${ }^{16}$ Therefore, while all investors demand a premium for the uncertain price change that the CSR disclosure creates, only type-2 investors demand

\footnotetext{
${ }^{15}$ In discussing expected returns, we assume the parameters are such that $p_{1}>0$ so a positive expected return implies $E\left[p_{2}\right]>p_{1}$.

${ }^{16}$ The cost of capital in Corollary 2 is increased by type-2 investors, and is increasing in $\lambda$. This is similar in spirit to the result in Bloomfield and Fischer (2011, p. 53) that "cost of capital is increased by the extent to which each type believes the other is responding to data that are not value relevant."
} 
a premium for holding CSR related risk in the second round of trading. Specifically, in round 2 a fraction $\lambda\left(1+(1-\lambda) \frac{\tau_{x}^{\prime}}{\tau_{y}^{\prime}}\right)^{-1}$ of shares are held by type- 2 investors. Only these investors respond to the CSR disclosure such that the variance of the price driven by type2 investors reacting to information is proportional to $\left(\lambda\left(1+(1-\lambda) \frac{\tau_{x}^{\prime}}{\tau_{y}^{\prime}}\right)^{-1}\right)^{2}$. Similar to the cash flow related risk, the discount in $p_{1}$ for CSR risk is the sum of the discount in the second round, $\frac{\lambda}{1+(1-\lambda) \frac{\tau_{x}^{\prime}}{\tau_{y}^{\prime}}} r \frac{1}{\tau_{y}^{\prime}}$, and the CSR related variance in the second round price, $\left(\lambda\left(1+(1-\lambda) \frac{\tau_{x}^{\prime}}{\tau_{y}^{\prime}}\right)^{-1}\right)^{2} r \frac{1}{\tau_{y}^{\prime}} \frac{\tau_{n}}{\tau_{y}}$.

Finally, following the impact of cash flow related risks on the shareholder base that we discussed in Corollary 1, the cash flow risk that remains after the disclosure impacts the pricing of CSR based risk. For example, when the cash flow disclosure is perfectly precise (i.e., when $\tau_{x}^{\prime}$ approaches positive infinity) then all shares in the second round will be held by type- 1 investors and price does not change as a response to the CSR disclosure (that is, $\left.\lim _{\tau_{m} \rightarrow \infty} E\left[p_{2}-p_{1}\right]=r / \tau_{x}\right)$. That is, the precision of cash flow disclosure determines the pricing of the CSR disclosure.

Since investors react to the disclosure of information, the price in Proposition 2 encompasses reaction coefficients to the two disclosed signals. While there is ample literature on earnings response coefficients (Kothari (2001) provides a review), to our knowledge we are the first to analytically develop a response coefficient to CSR disclosure. Proposition 3 analyzes the market response to CSR disclosure.

Proposition 3 The price reaction to CSR disclosure is determined by the following response coefficient

$$
\alpha=\frac{\tau_{n}}{\tau_{y}+\tau_{n}} * \frac{\lambda}{1+(1-\lambda) \frac{\tau_{x}+\tau_{m}}{\tau_{y}+\tau_{n}}} .
$$

The CSR response coefficient increases in the precision of CSR disclosure and in the fraction of type-2 investors. The CSR response coefficient decreases in the precision of financial disclosure, the prior precision of cash flows, and the prior precision of the CSR outcome. That is, $\frac{d \alpha}{d \tau_{n}} \geq 0, \frac{d \alpha}{d \lambda} \geq 0, \frac{d \alpha}{d \tau_{m}} \leq 0, \frac{d \alpha}{d \tau_{x}} \leq 0$, and $\frac{d \alpha}{d \tau_{y}} \leq 0$. 
Proposition 3 shows that some of the conjectures from the literature on earnings response coefficients carry over to our CSR response coefficient. That is, a higher precision of the report and a lower ex ante precision of CSR outcomes increase the price reaction to the CSR disclosure. Intuitively, a higher fraction of investors who are interested in CSR performance increases the price response to the disclosure. Furthermore, while CSR outcomes and cash flows are not correlated in our model, the characteristics of the financial disclosure have an impact on the price reaction to CSR disclosure. The reason is the endogenous shareholder base composition. Specifically, if the posterior precision of cash flows relative to CSR outcomes increases, then more shares will be held by type-1 investors, which reduces the price impact of the CSR disclosure.

The above discussion emphasizes the idea that the firm's shareholder base is an equilibrium outcome affected by prior beliefs and the arrival of information. This implies that information arrival causes investors to trade, giving rise to trading volume across investor types. Since shares will be sold from one type of investor to the other type, market clearing requires that $(1-\lambda)\left|q_{1,2}-q_{1,1}\right|=\lambda\left|q_{2,2}-q_{2,1}\right|$. Trading volume following the disclosure is therefore given by $T=(1-\lambda)\left|q_{1,2}-q_{1,1}\right|$. Substituting quantities and prices from equations 15. 18) yields the trading volume in Proposition 4.

Proposition 4 The trading volume in round 2 is given by

$$
T=\frac{\lambda(1-\lambda)}{1-\lambda+\frac{\tau_{y}+\tau_{n}}{\tau_{x}+\tau_{m}}}\left|1-\frac{\bar{y} \tau_{y}+n \tau_{n}}{r}\right| .
$$

First note that there is positive trading volume in our model even though all investors agree on the properties of the information, and no investor has access to private information or higher or lower processing costs. As such, trade in our setting is driven by heterogeneity in the valuation implications of the same information to investors with different tastes. When more information is disclosed regarding CSR outcomes and when the expected CSR outcome increases, then type-2 investors will increase their holdings in the firm by buying shares 
from type-1 investors. Additionally, it is evident from equation (21) that volume around an information arrival (e.g., a corporate disclosure) is non-monotonic in the surprise related to the outcome that is valued heterogeneously by investors, i.e., $|n-\bar{y}|$. Indeed, equation (21) suggests that there is a range over which trading volume is actually decreasing in the surprise. Finally, note that while a more precise cash flow disclosure always increases trading volume, this need not be the case with a more precise CSR disclosure.

\section{Discussion and conclusion}

\subsection{Empirical Implications}

Our results have a number of empirical implications for researchers interested in the capital market implications of firms' CSR activities and their disclosures about these activities. We discuss empirical implications of our model under alternative interpretations (e.g., where $\tilde{y}$ represents other dimensions of investor taste) in the next subsection. All of the empirical implications we highlight are driven by shareholder base effects that follow from our assumption of heterogeneous investor taste.

First, we find that investor tastes can cause firms' market values to be increasing in the riskiness of their cash flows, in contrast to the usual result that market value is decreasing in cash flow risk. This is not a general result, but rather occurs only when the expected CSR outcomes are sufficiently positive. The mechanism underlying this result involves cash flow risk deterring type-1 investors, allowing type- 2 investors who value the firms' high expected CSR outcome to have a more significant influence on the firm's share price. Empirically, this result can be operationalized in settings where CSR outcomes are likely to be a significant driver of investment choices 17

Second, we predict that market responses to disclosures about CSR will be stronger

\footnotetext{
${ }^{17}$ While this is unlikely to be descriptive of national stock markets like the NYSE, it is plausibly descriptive in novel online markets like Kiva, which connects lenders and borrowers online with the explicit goal of reducing poverty and has facilitated over $\$ 600$ million in loans from 2005 through mid-2014.
} 
when the quality of (potentially concurrent) disclosures about fundamentals is lower. This results from the mix of type- 1 and type- 2 investors in the marketplace. When the quality of financial information is higher, more of the firm's shares are held by type- 1 investors. The response to CSR disclosure is muted because a smaller fraction of the firm's shareholder base values CSR performance. Additionally, when the market is primarily composed of either all type-1 or all type-2 investors, there is little scope for shareholder base effects. Therefore, the relation between market responses to CSR disclosures and the quality of cash-flow disclosures is expected to be greatest when there are significant portions of both type- 1 and type- 2 investors, and weakest when the market is dominated by either type- 1 or type-2 investors (i.e., $\lambda=0$ or $\lambda=1$ ). These predictions can be operationalized in public stock markets with data on investor holdings (e.g., holdings of socially responsible funds) and proxies for the quality of CSR and fundamental disclosures.

In a setting where CSR disclosures are informative about cash flows, we would also expect to find a negative relation between the market response to CSR disclosures and the quality of disclosures explicitly about fundamentals. To illustrate, consider a firm that discloses a signal about fundamentals, $\tilde{m}=\tilde{x}+\tilde{\varepsilon}_{m}$, as above, in a setting without type-2 investors, such that CSR disclosures are used only to make inferences about cash flows. In this example, market returns would be associated with the CSR disclosure as long as there is noise in the disclosure about fundamentals (i.e., $\operatorname{Var}\left[\varepsilon_{m}\right] \neq 0$ ). As the noise in the disclosure about fundamentals goes to zero the incremental information from the CSR disclosure disappears and the market ceases to react to the CSR disclosure. This mechanism, of substitution between informative signals, however, is very different from the mechanism we identify based on shareholder base effects. We caution that an empirical study finding a market price reaction to CSR disclosures should be wary about inferring that CSR disclosures are informative about cash flows, because such a reaction could be driven by investor tastes and shareholder base effects. An effective empirical strategy to disentangle the two competing explanations could test whether the distribution of the shareholder base affects the negative relation between market 
reactions to CSR disclosures and the quality of disclosures about fundamentals. The effect we identify is significant only with a mix of type- 1 and type-2 investors, while the alternative explanation based on signal substitution should be independent of the mix of shareholders.

Third, we show that the existence of investor tastes can lead to corporate spin-offs where a company decides to split off a section of its business and to list it independently. Such a spin-off can increase the market value of the original firm's equity. The reason for the potential stock market benefit is that the shareholder base of the two individual companies does not have to equal the shareholder base of the original company. Because the shareholder base can readjust, splitting the firm allows investors to improve risk sharing, which reduces the combined risk premium of both firms. However, the improvement in risk sharing has a second effect: the expected CSR performance receives a different weight in the combined prices of the split firms. This implies that companies should have a bigger incentive to spin off "sin stocks" than they do to spin off business segments that have a very positive social impact.

Fourth, while we do not provide analytical results for this, our analysis provides a channel for individual social responsibility to yield corporate social responsibility ${ }^{18}$ The channel that we derive is the impact of taste on the firm's stock price. That is, managers who are interested in maximizing stock price have an incentive to invest in projects that yield a positive CSR outcome even if they are not cash flow maximizing. An investigation of the single-period stock price suggests that incentives to invest in CSR projects increase in the fraction of type2 investors and in cash-flow uncertainty but decrease in CSR uncertainty. In line with the first prediction, Naughton et al. (2014) find that in periods of higher investor sentiment (or taste) for CSR, managers increase their CSR investment and that this investment does not result in high future returns.19 The second and third predictions further suggest that firms'

\footnotetext{
${ }^{18}$ For a more detailed analysis of a firm's investment decision when some investors value CSR, see Gollier and Pouget (2012). They assume that the CSR outcome is certain, conditional on the firm's investment choice, and their results would also hold in our model if we assumed no CSR risk.

${ }^{19}$ As a measure for investor sentiment, Naughton et al. (2014) compare the market value of firms with high and low CSR performance. They assume that when this difference is high, investor sentiment for CSR is strong. In the context of our model, the sentiment measure could measure the fraction of investors that
} 
investments in CSR are complementary with CSR disclosures and dis-complementary with fundamental or cash flow disclosure quality. Essentially, when firms improve their expected CSR outcomes (potentially at the expense of expected cash flows), they want the market to place more weight on CSR and less weight on cash flows. Firms can achieve this goal by improving the quality of CSR disclosures to attract more type-2 investors, or by weakening the quality of cash flow disclosures to deter type- 1 investors and increase the proportion of type-2 investors. We therefore predict that firms engaged in CSR activities will tilt their disclosure strategies to emphasize CSR and, if possible, weaken the quality of disclosures about fundamentals. Relatedly, if changes in disclosure standards increase the quality of mandated CSR disclosures, we predict that firms will invest more in CSR activities, even at the expense of expected cash flows valued by all investors.

Fifth, with a slight extension, our model is consistent with the existence and increasing prevalence of mutual funds that choose not to invest in firms with poor expected CSR performance (e.g., the Vanguard FTSE Social Index Fund). Specifically, if we were to introduce short-sale restrictions (a la Jarrow, 1980), then a firm with very poor expected CSR performance would in equilibrium be held only by type- 1 investors. That is, investors concerned about CSR would, in the presence of short-sale restrictions, optimally hold zero shares of this type of firm. An additional implication of a short-sale restriction is that firms with sufficiently high expected CSR performance relative to cash flows would be held only by type-2 investors. If cash flows to investors are zero, these firms could be labeled charities, who receive donations from type-2 investors primarily motivated by expectations of positive CSR performance. Even with non-zero cash flows, the assets we model could represent lotteries designed for charitable fund-raising (see, e.g., Landry et al., 2006; Lange et al., 2007).

Sixth, our model helps explain trading volume around informative disclosures, announcements, or other news events. Heterogeneous taste provides a natural foundation for investors using the same information to update private valuations differently, which then drives trade have a taste for CSR or how much utility type 2 investors receive from CSR output. 
as investors efficiently rebalance their portfolios.

Finally, our model can help explain the potential for firms with positive expected CSR performance to have greater stock market returns than firms with zero or negative expected CSR performance. Petruno (2014) describes how members of the millenial generation are "embracing 'socially responsible' investing," and are entering "their prime saving and investing years, and potentially inherit[ing] trillions of dollars." If the proportion of CSR-sensitive investors $(\lambda)$ is increasing over time, then the weight on expected risk-adjusted CSR performance $\left(\bar{y}-r \sigma_{y}^{2}\right)$ in the pricing function will also be increasing over time. Koh et al. (2014) suggest that investors pay a premium for "saints" (identified by a social index) and ask for a discount to buy sinners (alcohol, gambling, tobacco). An increase in the proportion of investors that do so will cause an increase in price for positive-CSR firms (i.e., with $\bar{y}-r \sigma_{y}^{2}>0$ ) independent of a relation between CSR performance and cash-flow performance.

\subsection{Alternative interpretations beyond CSR}

Finally, we discuss applications of our model to areas beyond CSR where investor tastes have been shown to have an impact on demand for shares. Several empirical studies have documented areas in which differences in investors' preferences affect stock ownership in the cross-section. Graham and Kumar (2006) find evidence for age and tax clienteles related to dividends, whereby older and lower-income retail investors display a stronger preference for dividend yields than younger and higher-income retail investors. Jacob et al. (2014) show that heterogeneous tax-based preferences across owners of closely-held firms affect dividend policy. ${ }^{20}$ Harris et al. (2014) find evidence supporting heterogeneous preferences over payout policies (dividends vs. capital gains), independent of and often in conflict with potential

\footnotetext{
${ }^{20}$ Taste differences in our model are closely related to the effects of tax clienteles (e.g., Allen et al., 2000) but differ for a substantive reason. In our model, $\tilde{y}$ could represent the extra after-tax payout to investors facing lower marginal tax rates. In a model that captures tax-based clienteles, $\tilde{x}$ and $\tilde{y}$ would have to be perfectly correlated, because differential income tax treatment of equity distributions implies that payouts to one group are proportional to (i.e., perfectly correlated with) payouts to the other groups. We assume that $\tilde{x}$ and $\tilde{y}$ are orthogonal to ensure that type- 1 investors cannot use $\tilde{y}$ to learn about $\tilde{x}$ so that only type- 2 investors incorporate information about $\tilde{y}$ into their valuations.
} 
wealth-based preferences over the same payout policies. Grinblatt and Keloharju (2000) find that different classes of investors (local vs. foreign) display heterogeneous preferences for recent stock returns (engaging in momentum vs. contrarian investing strategies). Grinblatt and Keloharju (2001) document investor preferences based on cultural and language similarity to management. Bushee (2001) finds that institutional investors with shorter horizons display a preference for near-term earnings relative to long-term value. The investment "home bias" is a pervasive phenomenon, whereby investors prefer to invest in local stocks rather than foreign or distant stocks (e.g., Coval and Moskowitz, 1999; Huberman, 2001). While we focus on CSR, our non-cash-flow outcome could straightforwardly be adapted to one of the applications above.

Investor tastes could also be related to insider status. Cohen (2009) finds that employee loyalty influences individuals' portfolio preferences in favor of holding their employers' stock. Insiders who obtain private benefits of control also can be interpreted as having additional tastes for owning shares beyond cash flows available to all investors (e.g., Barclay and Holderness, 1989; Dyck and Zingales, 2004). An important difference is that private benefits of control often involve information asymmetry between insiders and outsiders, which would be between type-1 and type-2 investors in our model. Adding such information asymmetry would complicate our model and potentially alter some of our findings related to the importance of shareholder base.

\subsection{Conclusion}

This paper presents a simple model that examines the capital market implications of heterogeneous investor taste. We link heterogeneous tastes to several predictions related to asset prices, returns, and firms' investment choices. Our results have implications for researchers and practitioners interested in investor clienteles (i.e., shareholder base effects) and how endogenous clienteles affect returns, reactions to information, firms' investment trade-offs, and diversification. Our model also highlights the importance of distinguishing between firm 
value based on market prices and fundamental value based on discounted cash flows. In other words, when investors have taste for non-financial output, maximizing shareholder value is not equivalent to maximizing the discounted value of cash flows. 


\section{References}

Allen, F., A. E. Bernardo., and I. Welch. 2000. A theory of dividends based on tax clienteles. The Journal of Finance 55(6): 2499-2536.

Andreoni, J. 1989. Giving with impure altruism: Applications to charity and ricardian equivalence. Journal of Political Economy 97(6): 1447-1458.

Bagnoli, M., and S. G. Watts. 2014. Voluntary assurance of voluntary CSR disclosure. Purdue University working paper.

Barclay, M. J., and C. G. Holderness. 1989. Private benefits from control of public corporations. Journal of Financial Economics 25(2): 371-395.

Baron, D. P. 2007. Corporate social responsibility and social entrepreneurship. Journal of Economics \& Management Strategy 16(3): 683-717.

Baron, D. P. 2009. A positive theory of moral management, social pressure, and corporate social performance. Journal of Economics \& Management Strategy 18(1): 7-43.

Bénabou, R., and J. Tirole. 2010. Individual and corporate social responsibility. Economica 77(305): 1-19.

Berger, P. G., and E. Ofek. 1995. Diversification's effect on firm value. Journal of Financial Economics 37(1): 39-65.

Bloomfield, R., and P. E. Fischer. 2011. Disagreement and the cost of capital. Journal of Accounting Research 49(1): 41-68.

Brock, J. M., A. Lange., and E. Y. Ozbay. 2013. Dictating the risk: Experimental evidence on giving in risky environments. American Economic Review 103(1): 415-437.

Bushee, B. J. 2001. Do institutional investors prefer near-term earnings over long-run value? Contemporary Accounting Research 18(2): 207-246.

Cheng, B., I. Ioannou., and G. Serafeim. 2014. Corporate social responsibility and access to finance. Strategic Management Journal 35(1): 1-23.

Clark, G. L., and M. Viehs. 2014. The implications of corporate social responsibility for investors. University of Oxford working paper.

Cohen, L. 2009. Loyalty-based portfolio choice. Review of Financial Studies 22(3): 12131245 .

Coval, J. D., and T. J. Moskowitz. 1999. Home bias at home: Local equity preference in domestic portfolios. The Journal of Finance 54(6): 2045-2073.

Dhaliwal, D. S., O. Z. Li., A. Tsang., and Y. G. Yang. 2011. Voluntary nonfinancial disclosure and the cost of equity capital: The initiation of corporate social responsibility reporting. The Accounting Review 86(1): 59-100. 
Dhaliwal, D. S., S. Radhakrishnan., A. Tsang., and Y. G. Yang. 2012. Nonfinancial disclosure and analyst forecast accuracy: International evidence on corporate social responsibility disclosure. The Accounting Review 87(3): 723-759.

Di Giuli, A., and L. Kostovetsky. 2014. Are red or blue companies more likely to go green? Politics and corporate social responsibility. Journal of Financial Economics 111(1): 158180.

Dyck, A., and L. Zingales. 2004. Private benefits of control: An international comparison. The Journal of Finance 59(2): 537-600.

Exley, C. L. 2015. Excusing selfishness in charitable giving: The role of risk. Working paper.

Fama, E. F., and K. R. French. 2007. Disagreement, tastes, and asset prices. Journal of Financial Economics 83(3): 667-689.

Gollier, C., and S. Pouget. 2012. Asset prices and corporate behavior with socially responsible investors. Working paper.

Graff Zivin, J., and A. Small. 2005. A Modigliani-Miller theory of altruistic corporate social responsibility. Topics in Economic Analysis and Policy 5(1).

Graham, J. R., and A. Kumar. 2006. Do dividend clienteles exist? Evidence on dividend preferences of retail investors. The Journal of Finance 61(3): 1305-1336.

Grinblatt, M., and M. Keloharju. 2000. The investment behavior and performance of various investor types: a study of Finland's unique data set. Journal of Financial Economics 55(1): $43-67$.

Grinblatt, M., and M. Keloharju. 2001. How distance, language, and culture influence stockholdings and trades. The Journal of Finance 56(3): 1053-1073.

Hakansson, N. H., J. G. Kunkel., and J. A. Ohlson. 1982. Sufficient and necessary conditions for information to have social value in pure exchange. The Journal of Finance 37(5): $1169-1181$.

Harris, L., S. M. Hartzmark., and D. H. Solomon. 2014. Juicing the dividend yield: mutual funds and the demand for dividends. Journal of Financial Economics, Forthcoming.

Harris, M., and A. Raviv. 1993. Differences of opinion make a horse race. Review of Financial Studies 6(3): 473-506.

Hawn, O., A. Chatterji., and W. Mitchell. 2014. How firm performance moderates the effect of changes in status on investor perceptions: additions and deletions by the Dow Jones Sustainability Index. Working paper.

He, X.-Z., and L. Shi. 2012. Disagreement, correlation and asset prices. Economics Letters 116(3): 512-515. 
Hirigoyen, G., and T. Poulain-Rehm. 2014. Relationships between corporate social responsibility and financial performance: What is the causality? Working paper.

Huang, X., and L. Watson. 2015. Corporate social responsibility research in accounting. Journal of Accounting Literature, Forthcoming.

Huberman, G. 2001. Familiarity breeds investment. Review of Financial Studies 14(3): 659-680.

Jacob, M., R. Michaely., and A. Alstadsæter. 2014. Taxation and dividend policy: The muting effect of diverse ownership structure. University of Oslo working paper.

Jarrow, R. 1980. Heterogeneous expectations, restrictions on short sales, and equilibrium asset prices. The Journal of Finance 35(5): 1105-1113.

Kim, J.-B., B. Li., and Z. Liu. 2014. Does social performance influence breadth of ownership? Working paper.

Kim, O., and R. E. Verrecchia. 1994. Market liquidity and volume around earnings announcements. Journal of Accounting and Economics 17(1): 41-67.

Koh, S., R. B. Durand., and M. Limkriangkrai. 2014. The value of saints and the price of sin. Pacific-Basin Finance Journal, In Press.

Kondor, P. 2012. The more we know about the fundamental, the less we agree on the price. Review of Economic Studies 79(3): 1175-1207.

Kothari, S. 2001. Capital markets research in accounting. Journal of Accounting and Economics 31: $105-231$.

Lam, S.-S., W. Zhang., and G. H. Jacob. 2015. The mispricing of socially ambiguous grey stocks. Working paper.

Lambert, R., C. Leuz., and R. E. Verrecchia. 2007. Accounting information, disclosure, and the cost of capital. Journal of Accounting Research 45(2): 385-420.

Landry, C. E., A. Lange., J. A. List., M. K. Price., and N. G. Rupp. 2006. Toward an understanding of the economics of charity: Evidence from a field experiment* The Quarterly Journal of Economics 121(2): 747-782.

Lange, A., J. A. List., and M. K. Price. 2007. Using lotteries to finance public goods: Theory and experimental evidence. International Economic Review 48(3): 901-927.

Lintner, J. 1969. The aggregation of investor's diverse judgments and preferences in purely competitive security markets. Journal of Financial and Quantitative Analysis 4(04): 347400.

Martin, P., and D. Moser. 2014. Managers' green investment and related disclosure decisions. Technical report. University of Pittsburgh working paper. 
Milgrom, P., and N. Stokey. 1982. Information, trade and common knowledge. Journal of Economic Theory 26(1): 17-27.

Naughton, J. P., C. Wang., and I. Yeung. 2014. Are CSR expenditures affected by investor sentiment? Northwestern University working paper.

Petruno, T. 2014, December 7. Beyond profits: Millennials embrace investing for social good. Los Angeles Times.

Rahi, R., and J. P. Zigrand. 2014. Information aggregation in a competitive economy. London School of Economics working paper.

Robinson, M., A. Kleffner., and S. Bertels. 2011. Signaling sustainability leadership: Empirical evidence of the value of DJSI membership. Journal of Business Ethics 101(3): $493-505$.

Rubinstein, M. 1974. An aggregation theorem for securities markets. Journal of Financial Economics 1(3): 225-244.

Rubinstein, M. 1975. Securities market efficiency in an arrow-debreu economy. The American Economic Review 65(5): 812-824.

Serafeim, G. 2014. Integrated reporting and investor clientele. Harvard Business School working paper. 


\section{A Proofs}

Lemma 1; The first order condition to (1) with respect to demand in shares of the risky asset for an investor of type $i$ is given by

$$
E\left[\tilde{v}_{i}\right]-p-r q_{i} \operatorname{Var}\left[\tilde{v}_{i}\right]=0
$$

Solving this for $q_{i}$ yields the demands in (2). Substituting $q_{i}$ into the market clearing condition and solving for $p$ proves the claim.

Corollary 1: The expressions for the comparative statics are

$$
\begin{aligned}
\frac{d p}{d \bar{y}} & =\frac{\lambda \sigma_{x}^{2}}{\sigma_{x}^{2}+(1-\lambda) \sigma_{y}^{2}}>0, \\
\frac{d p}{d \sigma_{y}^{2}} & =\frac{-\left(\bar{y}(1-\lambda)+r \sigma_{x}^{2}\right) \lambda \sigma_{x}^{2}}{\left(\sigma_{x}^{2}+\sigma_{y}^{2}(1-\lambda)\right)^{2}} \gtrless 0, \\
\frac{d p}{d \lambda} & =\frac{\left(\bar{y}-r \sigma_{y}^{2}\right)\left(\sigma_{x}^{2}+\sigma_{y}^{2}\right) \sigma_{x}^{2}}{\left(\sigma_{x}^{2}+\sigma_{y}^{2}(1-\lambda)\right)^{2}} \gtrless 0, \text { and } \\
\frac{d p}{d \sigma_{x}^{2}} & =-\frac{r\left(\sigma_{x}^{4}+\sigma_{y}^{4}(1-\lambda)+2 \sigma_{y}^{2} \sigma_{x}^{2}(1-\lambda)\right)-\sigma_{y}^{2} \lambda \bar{y}(1-\lambda)}{\left(\sigma_{y}^{2}(1-\lambda)+\sigma_{x}^{2}\right)^{2}} \gtrless 0 .
\end{aligned}
$$

Proposition 1: To prove the claim, we first derive equations (9) and (10). Investors utility can be expressed as $u_{i}=-\exp \left\{r\left(\mathbf{q}_{i}^{T} \mathbf{v}_{i}+l_{i}\right)\right\}, i \in\{1,2\}$ where $r$ is their level of risk aversion, $\mathbf{q}_{i}=\left(q_{i, k}, q_{i, a}\right)^{T}$ represents the $2 \times 1$ vector of investor $i$ 's demand for shares in the 2 firms, $\tilde{\mathbf{v}}_{1}=\tilde{\mathbf{x}}=\left(\tilde{x}_{k}, \tilde{x}_{a}\right)^{T}$, and $\tilde{\mathbf{v}}_{2}=\tilde{\mathbf{x}}+\tilde{\mathbf{y}}=\left(\tilde{x}_{k}, \tilde{x}_{a}+\tilde{y}\right)^{T}$. Each investor maximizes her expected terminal utility subject to the budget constraint

$$
w_{i}=\mathbf{q}_{i}^{T} \mathbf{P}+l_{i},
$$

where $w_{i}$ is the initial wealth endowment and $\mathbf{P}=\left(p_{k}, p_{a}\right)^{T}$ is the price vector. Note that the price per share of the risk-free asset, like its return, has been normalized to one. Substituting the budget constraint, it is straightforward to show that maximizing expected utility is 
equivalent to maximizing the following certainty equivalent

$$
C E_{i}=\mathbf{q}_{i}^{T}\left(E\left[\mathbf{v}_{i}\right]-\mathbf{P}\right)-\frac{1}{2} r \mathbf{q}_{i}^{T} \operatorname{Cov}\left[\mathbf{v}_{i}\right] \mathbf{q}_{i}
$$

where $\operatorname{Cov}\left[\mathbf{v}_{1}\right]=\Sigma_{x}$ and $\operatorname{Cov}\left[\mathbf{v}_{1}\right]=\Sigma_{x}+\Sigma_{y}$, with

$$
\boldsymbol{\Sigma}_{x}=\operatorname{Cov}\left[\left(\tilde{x}_{k}, \tilde{x}_{a}\right)\right]=\left[\begin{array}{cc}
\sigma_{x_{k}}^{2} & 0 \\
0 & \sigma_{x_{a}}^{2}
\end{array}\right] \text { and } \boldsymbol{\Sigma}_{y}=\left[\begin{array}{cc}
0 & 0 \\
0 & \sigma_{y}^{2}
\end{array}\right] \text {. }
$$

Note that equation (27) below holds with non-zero covariance terms in $\Sigma_{x}$ and $\Sigma_{y}$ and non-zero variance for firm $k$ 's CSR performance as long as the covariance matrices remain positive-definite. The first order condition for an investor of type $i$ choosing share quantities to maximize wealth is given by

$$
E\left[\mathbf{v}_{i}\right]-\mathbf{P}-\operatorname{rCov}\left[\mathbf{v}_{i}\right] \mathbf{q}_{i}=0,
$$

such that the optimal demand for a type-i investor is given by

$$
\mathbf{q}_{i}=\frac{1}{r} \operatorname{Cov}\left[\mathbf{v}_{i}\right]^{-1}\left(E\left[\mathbf{v}_{i}\right]-\mathbf{P}\right)
$$

Prices are set such that aggregate demand equals aggregate supply. We assume that there is 1 share of each firm per investor and denote $\mathbf{1}=(1,1)^{T}$ the supply vector in the 2-firm case. Therefore, it has to be the case that, on average, $(1-\lambda) \mathbf{q}_{1}+\lambda \mathbf{q}_{2}=\mathbf{1}$. Substituting the optimal demands yields

$$
\frac{1-\lambda}{r} \operatorname{Cov}\left[\mathbf{v}_{1}\right]^{-1}\left(E\left[\mathbf{v}_{1}\right]-\mathbf{P}\right)+\frac{\lambda}{r} \operatorname{Cov}\left[\mathbf{v}_{2}\right]^{-1}\left(E\left[\mathbf{v}_{2}\right]-\mathbf{P}\right)=\mathbf{1} .
$$


Substituting our terms for output moments and solving for the price vector yields

$$
\mathbf{P}=\overline{\mathbf{x}}+\left((1-\lambda) \boldsymbol{\Sigma}_{x}^{-1}+\lambda\left(\boldsymbol{\Sigma}_{x}+\boldsymbol{\Sigma}_{y}\right)^{-1}\right)^{-1}\left(\lambda\left(\boldsymbol{\Sigma}_{x}+\boldsymbol{\Sigma}_{y}\right)^{-1} \overline{\mathbf{y}}-r \mathbf{1}\right) .
$$

Equations (9) and (10) in the text follow directly from (29). First, substitute (8), (9), and (10) into $p_{k}+p_{a} \geq p_{u}$. Substituting $r \sigma_{y}^{2}>\bar{y}, \lambda=0, \lambda=1$, or $r \sigma_{y}^{2}=\bar{y}$ proves the claim.

Proposition 2; Expected price in period 2 is defined by $E[\tilde{m}]=\bar{x}$ and $E[\tilde{n}]=\bar{y}$ as

$$
E\left[p_{2}\right]=\bar{x}-r \frac{1}{\tau_{x}+\tau_{m}}+\lambda\left(\frac{\bar{y}\left(\tau_{y}+\tau_{n}\right)-r}{\tau_{y}+\tau_{n}+(1-\lambda)\left(\tau_{x}+\tau_{m}\right)}\right) .
$$

The expected change in price is therefore:

$$
\begin{aligned}
E\left[p_{2}-p_{1}\right]= & r \frac{\tau_{m}}{\tau_{x}\left(\tau_{m}+\tau_{x}\right)} \\
& +\lambda r \frac{\tau_{n}+(1-\lambda) \tau_{m}}{\left(\tau_{y}+(1-\lambda) \tau_{x}\right)\left(\tau_{y}+\tau_{n}+(1-\lambda)\left(\tau_{x}+\tau_{m}\right)\right)} \\
& +\lambda \bar{y} \frac{(1-\lambda)\left(\tau_{n} \tau_{x}-\tau_{m} \tau_{y}\right)}{\left(\tau_{y}+(1-\lambda) \tau_{x}\right)\left(\tau_{y}+\tau_{n}+(1-\lambda)\left(\tau_{x}+\tau_{m}\right)\right)}
\end{aligned}
$$

Corollary 2; Substituting (17) and (18) into $E\left[p_{2}-p_{1}\right]$ proves the claim.

Proposition 3: The respective derivatives are given by

$$
\begin{aligned}
\frac{d \alpha}{d \tau_{n}} & =\lambda \frac{(1-\lambda)\left(\tau_{m}+\tau_{x}\right)+\tau_{y}}{\left(\tau_{y}+\tau_{n}+(1-\lambda)\left(\tau_{x}+\tau_{m}\right)\right)^{2}} \geq 0, \\
\frac{d \alpha}{d \lambda} & =\frac{\tau_{n}\left(\tau_{m}+\tau_{n}+\tau_{x}+\tau_{y}\right)}{\left(\tau_{y}+\tau_{n}+(1-\lambda)\left(\tau_{x}+\tau_{m}\right)\right)^{2}} \geq 0, \\
\frac{d \alpha}{d \tau_{m}} & =\frac{-\lambda(1-\lambda) \tau_{n}}{\left(\tau_{y}+\tau_{n}+(1-\lambda)\left(\tau_{x}+\tau_{m}\right)\right)^{2}} \leq 0, \\
\frac{d \alpha}{d \tau_{x}} & =\frac{-\lambda(1-\lambda) \tau_{n}}{\left(\tau_{y}+\tau_{n}+(1-\lambda)\left(\tau_{x}+\tau_{m}\right)\right)^{2}} \leq 0, \text { and } \\
\frac{d \alpha}{d \tau_{y}} & =\frac{-\lambda \tau_{n}}{\left(\tau_{y}+\tau_{n}+(1-\lambda)\left(\tau_{x}+\tau_{m}\right)\right)^{2}} \leq 0 .
\end{aligned}
$$


Proposition 4: Substituting (16) and $\sqrt{15}$ into $T=(1-\lambda)\left|q_{1,2}-q_{1,1}\right|$ yields

$$
\begin{aligned}
T & =(1-\lambda)\left|\frac{E\left[\tilde{v}_{i} \mid m, n\right]-p_{2}}{r \operatorname{Var}\left[\tilde{v}_{i} \mid m, n\right]}-1\right| \\
& =(1-\lambda) \frac{\tau_{x}^{\prime}}{r}\left|-\frac{\lambda}{1+(1-\lambda) \frac{\tau_{x}^{\prime}}{\tau_{y}^{\prime}}}\left(\frac{\bar{y} \tau_{y}+n \tau_{n}}{\tau_{y}^{\prime}}-r \frac{1}{\tau_{y}^{\prime}}\right)\right| \\
& =\frac{\lambda(1-\lambda)}{1-\lambda+\frac{\tau_{y}+\tau_{n}}{\tau_{x}+\tau_{m}}}\left|1-\frac{\bar{y} \tau_{y}+n \tau_{n}}{r}\right|
\end{aligned}
$$

\section{B Non-zero correlation between $x$ and $y$}

This section discusses the baseline model when $x$ and $y$ are correlated, with $\operatorname{Cov}[\tilde{x}, \tilde{y}]=$ $\rho \sigma_{x} \sigma_{y}$ and $\rho \in[-1,1]$. While a type- 1 investor's certainty equivalent and, therefore, demand is not affected, a type-2 investor's certainty equivalent and demand are now

$$
\begin{aligned}
C E_{2} & =q_{2}(\bar{x}+\bar{y}-p)-\frac{1}{2} r q_{2}^{2}\left(\sigma_{x}^{2}+\sigma_{y}^{2}+2 \rho \sigma_{x} \sigma_{y}\right) \text { and } \\
q_{2} & =\frac{\bar{x}+\bar{y}-p}{r\left(\sigma_{x}^{2}+\sigma_{y}^{2}+2 \rho \sigma_{x} \sigma_{y}\right)} .
\end{aligned}
$$

The market-clearing condition is then given by

$$
(1-\lambda) \frac{\bar{x}-p}{r \sigma_{x}^{2}}+\lambda \frac{\bar{x}+\bar{y}-p}{r\left(\sigma_{x}^{2}+\sigma_{y}^{2}+2 \rho \sigma_{x} \sigma_{y}\right)}=1
$$

This implies that the equilibrium price is

$$
\begin{aligned}
p & =\bar{x}+\frac{\lambda \sigma_{x}^{2}}{\sigma_{x}^{2}+(1-\lambda)\left(\sigma_{y}^{2}+2 \rho \sigma_{x} \sigma_{y}\right)} \bar{y}-r \frac{\sigma_{x}^{2}\left(\sigma_{x}^{2}+\sigma_{y}^{2}+2 \rho \sigma_{x} \sigma_{y}\right)}{\sigma_{x}^{2}+(1-\lambda)\left(\sigma_{y}^{2}+2 \rho \sigma_{x} \sigma_{y}\right)} \\
& =\bar{x}-r \sigma_{x}^{2}+\frac{\lambda \sigma_{x}^{2}}{\sigma_{x}^{2}+(1-\lambda)\left(\sigma_{y}^{2}+2 \rho \sigma_{x} \sigma_{y}\right)}\left(\bar{y}-r\left(\sigma_{y}^{2}+2 \rho \sigma_{x} \sigma_{y}\right)\right) .
\end{aligned}
$$

This implies that an increase in the correlation, $\rho$, decreases the extent to which $\bar{y}$ is priced. The reason is that an increase in $\rho$ increases the perceived risk of type- 2 investors and, therefore, decreases their equilibrium holdings. The increase in perceived risk and the decrease in 
holdings have countervailing effects on the risk premium. However, the first effect dominates such that the risk premium increases when $\rho$ increases,

$$
\frac{\partial\left(r \frac{\sigma_{x}^{2}\left(\sigma_{x}^{2}+\sigma_{y}^{2}+2 \rho \sigma_{x} \sigma_{y}\right)}{\sigma_{x}^{2}+(1-\lambda)\left(\sigma_{y}^{2}+2 \rho \sigma_{x} \sigma_{y}\right)}\right)}{\partial \rho}=2 r \frac{\lambda \sigma_{x}^{5} \sigma_{y}}{\left(\sigma_{x}^{2}+(1-\lambda)\left(\sigma_{y}^{2}+2 \rho \sigma_{x} \sigma_{y}\right)\right)^{2}}>0
$$

This implies that when $\bar{y}>0$ then $\frac{d p}{d \rho}<0$. 